\title{
Strategi Pembelajaran Daring Dengan Model Resitasi Berbasis Teknologi Bagi Siswa MI/SD
}

\author{
Aisah Isnaeni \\ Institusi Agama Islam Negri Kudus,Indonesia \\ isnaeniaisah2@gmail.com \\ Eva Luthfi Fakhru Ahsani \\ Institusi Agama Islam Negri Kudus,Indonesia \\ evaluthfi@iainkudus.ac.id
}

\begin{abstract}
4.0 Revolution eases people to get connected online. It also influences the education development that goes in line with the information and communication technology advancement. One of the most-contributing in education world is online learning. This research aims to (a) describe the online learning strategy concept, (b) describe the technology based recitation model for learners, and (c) analyze the implementation of the online learning with technology based recitation model in NU Nurul Haq Islamic School, Prambatan, Kudus. This research uses a descriptive qualitative model from the interview results held online and face to face. The findings showed that online learning was effective to be implemented in current technologized era. Then, to make online learning running smoothly, there is a need of technology based tasks that could facilitate the online learning promotion by considering social, affective, cognitive, and psychomotor aspect. It is in accordance to technology based recitation model that could foster students' behaviors to seek and manage their information and communication. Furthermore, it could foster responsibility and discipline of the learners.
\end{abstract}

Keywords : Strategy, Online Learning, Technology based Recitation Model

\begin{abstract}
Abstrak
Revolusi 4.0 membuat orang mudah untuk terhubung melalui online. Hal ini juga akan mempengaruhi perkembangan pendidikan yang sejalan dengan pesatnya kemajuan teknologi informasi dan komunikasi. Salah satu teknologi yang ikut berperan dalam dunia pendidikan adalah pembelajaran daring. Sehingga tujuan penelitian ini yaitu: (a) mendeskripsikan konsep strategi pembelajaran daring, (b) mendeskripsikan model resitasi berbasis teknologi bagi siswa, (c) menganalisis penerapan strategi pembelajaran daring dengan model resitasi berbasis teknologi di MI NU Nurul Haq Prambatan Kudus. Model penelitian ini menggunakan model kualitatif deskriptif dari hasil wawancara yang diakukan secara online dan bertatap muka. Hasil dari peneltian penelitian menunjukan bahwa pembelajaran daring dirasa cukup efektif diterapkan dizaman sekarang yang serba teknologi. Kemudian
\end{abstract}


agar pembelajaran daring berjalan secara maksimal maka perlu adanya model penugasan berbasis teknologi yang mampu membuat pembelajaran daring berjalan dengan lancar dengan tetap memperhatikan nilai sosial, afektif, kognitif dan psikomotorik. Hal ini didasarkan pada model resitasi berbasis teknologi dapat membina kebiasaan siswa untuk mencari dan mengelola sendiri informasi dan komunikasi. Selain itu dapat membina tanggung jawab dan disiplin siswa.

Kata kunci: Strategi, Pembelajaran Daring, Model Resitasi Berbasis Teknologi.

\section{A. PENDAHULUAN}

Kegiatan pembelajaran baru atau modern yang mana pembelajarannya berbasis teknologi informasi memberikan dampak luasnya jangkauan yang sangat cocok jika diterapkan dalam masyarakat modern tanpa terbatas oleh situasi kondisi serta waktu dan tempat. Pada zaman sekarang revolusi industri 4.0 membuat orang mudah untuk terhubung melalui online. Banyak sekali contoh yang dapat dilihat, seperti semua media sosial yang dapat mengakses informasi dengan mudah dan cepat. Dalam kenyataannya masyarakat tidak akan gugup menghadapi suatu masalah jika sebelumnya sudah terbiasa memanfaatkan teknologi informasi. Seperti halnya dalam keadaan pandemik yang mempengaruhi seluruh dunia, yaitu adanya pandemik covid-19 yang mana masyarakat mau tidak mau harus mampu menguasai teknologi dan informasi. Ketika dalam keadaan seperti ini maka imbasnya juga dalam dunia pendidikan, yang mulanya belajar dilaksanakan dalam pertemuan tatap muka menjadi belajar dirumah. (Mustofa dkk., 2019)

Langkah yang dapat diambil dalam hal ini adalah pemanfaatan teknologi jaringan dan teknologi informasi baik pengembangan suatu kegiatan pembelajaran diseluruh dunia adalah penerapan strategi pembelajaran daring. Kegiatan pembelajaran daring mempunyai tujuan dimana pembelajaran daring dapat memberikan pelayanan yang bermutu yang sifatnya masif dan terbuka untuk dengan mudah menjangkau minat masyrakat yang lebih luas dan lebih banyak. Kegiatan daring akan mengkombinasikan antara pertemuan tatap muka dengan daring. Kegiatan daring akan dilaksanakan dengan cara mempersiapkan kegiatan pembelajaran yang membutuhkan keikutsertaan secara langsung antara siswa dan guru dalam proses pembelajaran. Sehingga tidak mewajibkan siswa untuk selalu belajar di dalam ruang kelas dengan segala peraturan yang kaku.(Sofyana \& Rozaq, 2019).

Teori pembelajaran konstruktivisme sesuai dengan keadaan saat ini bahwa ilmu pengetahuan perlu dibangun oleh murid melalui proses belajar, bukan hanya ditransfer dari guru ke murid. Mengingat hal tersebut tidak alasan untuk meragukan bahkan menolak pembelajaran daring. Dengan adanya sebuah tren yang berkembang di dunia serta melihat kondisi pendidikan di Indoneisia maka dapat dilihat alasan dibutuhkanya sebuah inovasi terbaru yaitu pembelajaran daring. Pembelajaran daring adalah kegiatan pembelajaran yang berlangsung 
melalui jaringan yang bisa dilakukan oleh siapa saja tanpa terbatas oleh waktu dan tempatnya. Sehingga diperlukan setiap mata pelajaran menyediakan materi dalam bentuk rekaman video atau slideshow, serta tugas-tugas mingguan yang harus dikerjakan dengan batas waktu pengerjaan yang telah ditentukan dengan beragam sistem penilaian.

Salah satu model pembelajaran yang dapat diaplikasikan untuk anak $\mathrm{MI} / \mathrm{SD}$ adalah pembelajaran daring dengan model penugasan atau resitasi. Model pembelajaran resitasi adalah model yang digunakan guru untuk menyampaikan sebua materi beserta tugas- tugas tertentu untuk digunakan siswa dalam melakukan kegiatan pembelajaran.model penyajian bahan dimana guru memberikan tugas tertentu agar siswa melakukan pembelajaran. Model resitasi ini dalam pelaksanaannya guru memberikan tugas yang sudah disiapkan sebelum diberikan kepada siswa untuk dikerjakan diluar jam pelajaran. Sehingga dalam pembelajaran daring tidak sedikit guru mengalami kesulitan ketika menerapkan sebuah metode-model pembelajaran yang biasa diterapkan saat tatap muka untuk diterapkan dalam pembelajaran daring. Ketika model yang biasa digunakan guru dalam tatap muka diterapkan dalam pembelajaran daring, maka suatu pembelajaran tersebut akan terhambat dalam berbagai kendala mulai dari jarngannya bahkan dari siswa sendiri. Apalagi untuk kelas rendah, maka dalam tatap muka siswa perlu bimbingan ekstra ketika guru menerapkan model yang variasi, apalagi dalam pembelajaran daring. Oleh sebab itu solusi yang dapat digunakan ketika penerapan pembelajaran daring adalah model resitasi. Dalam model resitasi siswa akan dituntut agar mampu memahami, merasakan dan menemukan secara langsung terhadap kegiatan belajar daring.

Pengaplikasian model resitasi berbasis teknologi dalam pembelajaran daring mampu meningkatkan hubungan antara guru dan siswa saat pembelajaran serta mempermudah mereka belajar dimana dan kapan saja, memiliki jangkauan yang sangat luas, memudahkan ketika menyimpan materi pembelajaran baik siswa maupun guru. Selain itu dengan adanya model resitasi berbasis teknologi maka mampu menciptakan susasana belajar yang nyaman karena memberikan kesempaatan belajar lebih baik dan cepat bagi siswa untuk memahami materi yang diajarkan.

Hasil penelitian yang telah dilakukan oleh Sari (2018) menunjukan bahwa penerapan resitasi dengan berbasis teknologgi informasi komunikasi dapat meningkatkan interaksi pembelajaran kapan dan dimana saja. Sesuai dengan penelitian terdahulu dapat disimpulkan bahwa pembelajaran menggunakan sosial media dapat mempermudah pelaksanaan pembelajaran. Tidak hanya whatshapp saja, belajar menggunakan sosial media yang lainnya juga bisa memperlancar pelaksanaan pembelajaran daring. Efektivitas penggunaan grup whatsapp mampu memberikan edukasi yang lebih baik dibandingkan menggunakan resitasi yang bersifat konvensional (Sari, 2018). Dari temuan ini dapat disimpulkan bahwa model pembelajaran menggunakan grup whatsapp berpengaruh posistif dan signifikan terhadap efektifitas belajar siswa (Humairoh, 2011). Berdasarkan 
uraian di atas, peneliti melakukan penelitian yang berjudul, "Strategi Pembelajaran Daring Dengan Model Resitasi Berbasis Teknologi Bagi Siswa MI/ SD".

\section{B. METODOLOGI}

Model yang digunakan dalam peneleitian ini adalah deskriptif kualitatif, yang mana subyek penelitian adalah guru kelas 2, siswa dan orang tua di MI NU Nurul Haq Prambatan Kudus. Pengumpulan data dalam peneltiian ini melalui wawancara yang meliputi bagaimana pembelajaran daring yang diterapkan di SD/MI, kemudian bagaiamana model penugasan dalam pembelajaran daring dan terakhir adalah bagaimana respon siswanya mengenai strategi daring dengan model resitasi siswa di SD/MI. Pada penelitian ini akan mengeksplorasi pengalaman guru dan siswa pada sistem terbatas kontemporer atau fokus satu kasus tertentu yaitu strategi pembelajaran daring dengan model resitasi berbasis teknologi bagi siswa MI/ SD.

Teknik pengumpulan data yang pakai peneliti yaitu pengamatan disekitar dan wawancara. Wawancara adalah percakapan antara pewawancara dengan narasumber yang dilakukan secara daring. Wawancara saat penelitian ini dilakukan terhadap guru kelas 2 MI NU Nurul Haq di Prambatan Lor, siswa dan orang tua dengan menggunakan wawancara terstruktur yang sebelumnya sudah dipersiapkan oleh pewawancara terlebih dahulu. Pengamatan dilakukan di rumah dengan siswa yang bersangkutan.

Analisis data dalam penelitian ini adalah analisis kualitatif dengan menggali data secara interaktif online dan terus menerus sampai tuntas akhirnya datanya sampai jenuh. Data yang sudah terkumpul lalu dianalisis melalui tiga tahap yaitu tahap reduksi verifikasi, data, dan display.

Penelitian ini termasuk dalam penelitian deskriptif kualitatif. Data yang diambil dalam pelaksanaan penelitian meliputi hasil observasi selama pembelajaran berlangsung untuk melihat bagaimana gambaran "Strategi Pembelajaran Daring dan Model Resitasi Berbasis Teknologi Bagi Siswa MI/ SD" dan data hasil kuesioner untuk melihat bagaimana kesiapan dan respon siswa melalui pelaksanaan strategi pembelajaran daring dengan model resitasi berbasis teknologi bagi siswa MI/ SD. Sasaran siswa pengguna pembelajaran daring dengaan model reitasi adalah 35 siswa kelas 2 MI NU Nurul Haq Prambatan. Hasil observasi dianalisis secara deskriptif kualitatif untuk dapat melihat bagaimana kelebihan dan kekurangan pelaksanaan strategi pembelajaran daring dengan model resitasi berbasis teknologi bagi siswa MI/ SD. Hasil observasi dianalisis secara deskriptif kualitatif untuk melihat bagaimana hasil pembelajaran strategi pembelajaran daring dengan model resitasi berbasis teknologi bagi siswa $\mathrm{MI} / \mathrm{SD}$. 


\section{HASIL DAN PEMBAHASAN}

Bagian ini Berdasarkan data yang diperoleh dari informasi guru kelas yang berada di Madrasah Ibtidaiyah, siswa kelas 2, dan orang tua. Selanjutnya dapat disajikan sebagai berikut:

\section{Strategi Pembelajaran Daring di MI/SD}

Pada penelitian ini dihasilkan data dari wawancara mengenai pembelajaran daring kombinasi model resitasi berbasis teknologi pada kelas 2 MI NU Nurul Haq. Pada zaman revolusi industri 4.0 saat ini, sebenarnya memudahkan orang untuk terhubung secara online jika kita sadari.. Seperti media sosial dan dapat mengakses informasi dengan cepat. Dalam kenyaataanmya masyarakat tidak akan gugup menghadapi suatu masalah jika sebelumnya sudah terbiasa memanfaatkan teknologi informasi. Seperti halnya dalam keadaan yang sanat mendunia ini yaitu adaanya wabah covid-19 yang mana masyarakat mau tidak mau harus mampu menguasai teknologi dan informasi. Ketika dalam keadaan seperti ini maka imbasnya juga dalam dunia pendidikan, yang mulanya belajar dilaksanakkan dalam pertemuan tatap muka menjadi belajar dirumah. Sehingga guru maupun siswa harus mampu mengikuti perkembangan dan kemajuan yang ada didepan mata yaitu dengan melaksanakan pembelajaran daring.

Langkah awal yang dilakukan dalam strategi pembelajaran daring adalah menggunakan sosial media. MI NU Nurul Haq melaksanakan pembelajaran daring ini menggunakan via whatsapp dan juga google form. Aktivitas ini tidak terlepas dengan peran wali murid dari siswa masingmasing. Hal ini tentulah menjadikan hubungan antara siswa dan orang tua menjadi lebih intensif. Oleh sebab itu strategi pembelajaran daring dapat merubah presepsi orang tua yang seperti itu.

Proses pembelajaran menggunakan daring dengan model resitasi berbaisi teknologi di MI NU Nurul Haq adalah membuat grup kelas di whatsapp yang berisi nomor dari guru serta wali murid kelas 2 MI NU Nurul Haq. Kemudian guru mengunggah materi dan tugas berbasis teknologi tersebut di via whatsap. Ketika ada wali murid yang masih bekerja pada saat guru memberikan materi dan tugas maka waktu akan menjadi flesksibel. Jadi siswa bisa mengunduh materi dan tugas melalui akun mereka masing-masing dengan waktu kapan saja. Jadi kebanyakan mereka yang orang tuanya sebagai ibu rumah tangga mereka akan mengikutinya secara tepat waktu sedangkan oarang tuanya yang masih bekerja, maka siswa akan belajar setelah orang tuaya pulang dari kerja. Maka dapat disimpulkan bahwa semua waktu dan tempat berjalan secara fleksibel.

Berjalannya strategi pembelajaran daring yang inovatif berbasis teknologi di MI NU Nurul Haq mengubah tatanan pembelajaran dalam madrasah ini yaitu, secara tidak sadar dengan adanya pembelajaran daring orang tua dan guru mampu mengikuti perubahan zaman yang serba teknologi. Imbasnya anak juga mempunyai nilai lebih dalam segi teknologi informasi 
komunikasi ketika pembelajaran dilaksnaakan dengan daring. Sehingga melahirkan anak-anak yang nantinya tidak akan gagal teknologi dimasa depannya.

Strategi pembelajaran daring MI NU Nurul Haq dari hasil penelitian bahwa tersedia fasilitas e-moderating dimana guru dan siswa dapat berkomunikasi secara mudah melalui fasilitas internet kemudian kapan dan dimananya. Kemudian guru dan siswa dapat menggunakan bahan ajar yang terstruktur dan terjadwal melalui internet. Selain itu siswa dapat belajar (mereview) bahan ajar setiap saat dan dimana saja apabila diperlukan mengingat bahan ajar tersimpan di komputer. Apabila siswa memerlukan tambahan informasi yang berkaitan dengan bahan yang dipelajarinya, ia dapat melakukan akses di internet. Baik guru maupun siswa dapat melakukan diskusi melalui internet yang dapat diikuti dengan jumlah peserta yang banyak. Hal terpenting adalah dengan adanya pembelajaran daring di madrasah MI NU Nurul Haq ini peran siswa dari yang pasif menjadi aktif, relatif lebih efisien. Misalnya bagi mereka yang tinggal jauh dari madrasah secara konvensional dapat mengaksesnya.

Kemudian titik fokus dalam pembelajaran daring yang dilaksanakan dirumah sesuai dengan hasil penelitian adalah lebih kearah bagaimana memaknai proses pendidikan. Proses pembelajaran ynag biasa terlalu diserahkan ke sekolah, maka pembelajaran daring membutuhkan peran serta dari orang tua dan orang-orang disekitar. Mengenai penanaman karakter dan lain sebagainya maka perlu adanya interaksi. Sedangkan isi dalam pembelajaran daring ini yang mulanya oriented menjadi proses maka yang diperlukan dalam pembelajaran daring adalah sebuah kreatifitas dan keaktifan antara guru dan siswa. Pembelajaran daring ditujukan agar meningkatnya literasi teknologi oleh guru, siswa, dan juga orang tua.

\section{Model Resitasi Berbasis Teknologi Bagi Siswa MI / SD}

Kendala yang dihadapi ketika pembelajaran daring adalah juga masalah jaringan serta bertabrakan dengan jam kerja orang tua. Sedangkan mengenai konten pembelajarannya yang menjadi kendala dari siswa maupun orang tua adalah work it, home work, dan tugas online yang diberikan waktu 1 minggu. Hal tersebut juga menjadi keluhan orangtua, padahal semestinya ketika menggunakan daring itu orangtua memegang berperan penting dalam mendampingi anak belajar di rumah.

Dari hasil penelitian mengenai sikap anak dalam menghadapi pembelajaran daring adalah mengikuti proses pembelajaran dengan baik dan aktif karena itu adalah tuntutan yang harus mereka ikuti. Menurut mereka pembelajaran daring adalah suatu hal yang baru namun baginya belajar di sekolah lebih menyenangkan karena bisa bertemu dengan teman-temannya secara langsung.

Jika dilihat dari yang mulanya menggunakan strategi pembelajaran tatap muka banyak staclholder yang mengeluh. Mulai dari guru yang harus 
berfikir keras akan adanya perubahan baru, kemudian orang tua yang harus selalu mendampingi anaknya sampai dari siswi yang mengeluh bosan untuk belajar daring dengan alasan banyak tugas dan tidak bisa bermain dengan temannya.

Oleh sebabnya alternatif yang dapat menjawab itu semua adalah guru harus menggunakan strategi pembelajaran daring dengan menggunakan model resitasi. Model resitasi apa yang dapat mengatasi semua keluhan dari siswa, yaitu model resitasi berbasis teknologi dimana penugasan menjadi sebuah inovasi bagi guru dan siswa serta orang tua. Inovasi dalam resitasi berbasis teknologi adalah penugasan yang memanfaatkan teknologi informasi dan komunikasi.

Dengan adanya resitasi atau penugasan dalam pembelajaran daring diharapakan siswa masih tetap belajar di rumah denngan baik. Banyaknya waktu dirumah ketika pembelajaran daring seperti halnya kondisi pada saat ini wabah covid-19 dikhawatirkan siswa menjadi malas belajar dan memilih untuk bermain. Oleh sebab itu resitasi atau penugasan berbasis teknologi ini adalah salah satu ynag sangat membantu ketika pembelajaran daring.

Dari hasil penelitian model resitasi atau penugasan berbasis teknologi ini sangat membantu dari pihak guru, siswa dan juga orang tua. Dengan adanya tugas maka siswa akan melewati proses pembelajaran yang akan memahamkan mereka pada sebuah materi pembelajaran yang disampaikan secara online. Alasan ketika model pemberian tugas dapat membuat siswa aktif belajar model ini lebih merangsang siswa untuk lebih banyak, baik waktu dikelas maupun diluar kelas atau dengan lain, baik siswa dekat dengan guru maupun jauh dengan guru. Model ini dapat menggembangkan kemandirian siswa yang diperlukan dalam kehidupannya. Tanpa disadari bahwa dengan adanya penugasan berbasis teknologi dapat membina kebiasaan siswa untuk mencari dan mengelola sendiri informasi dan komunikasi. Selain itu dapat membina tanggung jawab dan disiplin siswa.

Ketika ada problem siswa bosan belajar di rumah hanya mendapat materi secara online, maka model resitasi berbasis teknologi ini membuat siswa bergairah dalam belajar karena kegiatan kegiatan belajar dapat dilakukan dengan berbagai variasi sehingga tidak membosankan. Resitasi berbasis teknoligi ini bisa di aplikasikan seperti halnya tugas melalui foto dan video baik itu pengetahuan, ketrampilan, spiritual maupun sosial dengan memperhatikan mental dari siswanya sendiri. Sehingga siswa akan dengan senang hati ketika melaksanakan tugas tersebut. Tanpa mereka sadari bahwa pembelajaran konvesional yang biasa dilakukan di dalam sekolah itu jauh lebih membuat aktif siswa dalam proses pembelajaran dirumah berlangsung.

\section{Analisis Pembelajaran Daring dengan Model Resitasi Berbasis Teknologi Bagi Siswa MI/SD}

Salah satu bukti pemanfaatan teknologi dalam pembelajaran adala dengan melaksanakan pembelajaran daring pembelajaran daring berfungsi 
agar meminimalisir kekurangan yang biasa dilakukan secara tatap muka serta meminimalisir dalam keadaan pandemik yang terjadi di dunia. Dalam pembelajaran daring siswa terhubung dengan jaringan untuk mengakses beberapa materi yang diberikan oleh guru. Siswa dapat mengakses materi kapan dan dimana saja mereka berada.

Dalam penelitian proses pembelajaran dari rumah yang dilakukan secara daring berjalan baik dengan menggunakan resitasi yang berbasis teknologi. Proses pembelajaran daring tidak mengurangi sedikitpun siswa dalam menerima materi yang tetap mencakup nilai afektif, sosial, kognitif, dan psikomotorik. Hal ini karena guru menggunakan inovasi resitasi dengan teknologi sehingga membantu siswa dalam belajar menyerap pengetahuan dan juga nilai-nilai yang terkandung. Pembelajaran daring bukan hanya soal belajar dirumah saja akan tetapi sebuah pembelajaran dimana guru dapat mengemas suatu pembelajaran yang tidak biasa dilakukan sebelumnnya menjadi hal menarik untuk siswa. Pembelajaran daring memberikan banyak peluang kepada siswa untuk belajar lebih luas dan lebih mudah. Hal yang didapat siswa dalam pembelajaran daring sangat banyak seperti ketika siswa memerlukan tambahan informasi yang berkaitan dengan resitasi yang diberi oleh guru, siswa dengan mudah mempelajarinya, dengan melakukan akses di internet. Sehingga dalam proses pembelajaran daring mengunakan model resitasi membuat siswa tetap aktif dan dapat belajar dirumah, lebih merangsang siswa dalam melaksanakan aktifitas belajar yang fleksibel, dapat mengembangkan kemampuan kemandirian siswa di luar pengawasan guru, membina tanggung jawab \& disiplin siswa, menggembangkan kreatifitas siswa serta mengembangkan kreatifitas siswa.

\section{KESIMPULAN}

Kesimpulan Berasarkan hasil penelitian yang sudah dilakukan, maka dapat disimpulkan bahwa strategi pembelajaran yang biasanya yaitu tatap muka dinilai kurang efektif ketika muncul suatu inovasi yaitu pembelajaran daring. Pembelajaran yang fleksibel mmengenai waktu dan tempat adalah yang dibutuhkan siswa pada saat ini. Oleh sebab itu pembelajaran daring dinilai mampu membentuk jaringan yang baik antara guru, siswa dan orang tua. Dalam hasil penelitian meyebutkan bahwa agar pembelajaran di rumah tetap berjalan dengan lancar sesuai dengan prota dan promes maka diperlukannya suatu model penugasan berbasis teknologi yang mendukung mereka dalam memahami materi. Penugasan berbasis video ini yang menjadikan proses belajar di rumah itu tidak membosankan. Dengan adanya penugasan berbasis teknologi maka kreatifitas anak dan keaktifan anak, juga peran serta orang tua akan saling berjalan dengan sempurna. Solusi agar pembelajaran daring berjalan dengan baik maka perlu adanya kerjasama orang tua untuk saling memotivasi anak dalam belajar daring. 


\section{DAFTAR PUSTAKA}

Astuti, P., Febrian. (2019). Blended Learning Syarah Bagaimana Penerapan dan Persepsi Mahasiswa. Jurnal Gantang, IV (2). 111-119.

Elizabert. (2014). Collaborative Learning Techniques (teknik-teknik Pembelajaran Koraboratif. Bandung: Nusa Media..

Helmawati, (2014). Pendidikan Keluarga Teoretis dan Praktis. Bandung: PT Remaja Rosdakarya.

Humairoh. (2011). Pengaruh Model Pemberian Tugas dan Resitasi terhadap Hasil Belajar IPS Terpadu (Geografi) Siswa pada Kelas VII di MTs Daarul Hikmah Pamulang.

Skripsi. http://repository.uinjkt.ac.id/dspace/bitstream/123456789/2950/1/UMI\%20HUMAIR OH-FITK.pdf. Diakses 17 mei 2020

Ismail, M., Hadi, M.N. \& Sunaiyah, S. (2017). Model Penugasan dalam Pembelajaran PAI. Jurnal Podeena, 1.(2). 89-99.

Makmur, A.J. (2011). Tujuh tips aplikasi paikem. Jogjakarta: Diva press.

Mustofa, M.I., Chodzirin, M. \& Sayekt, L. (2019). Formulasi Model Perkuliahan Daring Sebagai Upaya Menekan Disparitas Kualitas Perguruan Tinggi. Journal of Information Technology, 1.(2), 6.

Purmadi, A., Hadi, M.S., Najwa, L. (2018). Pengembangan Kelas Daring Dengan Penerapan Hybrid Learning Menggunakan Chamilo Pada Matakuliah Pendidikan Kewarganegaraan. Jurnal Edcomtech, 3,(2).23.

Ramadhan, R., Chaeruman, U.A. \& Cecep Kustandi. (2018) Pengembangan Pembelajaran Bauran (Blended Learning) di Universitas Negeri Jakarta. Jurnal Pembelajaran Inovatif, 1 (1): 37 - 48.

Sari, S., Murjainah \& Tobar (2018). Pengaruh Model Pembelajaran Resitasi Berbasis Information Communication Technology (Ict) Terhadap Hasil Belajar Geografi Siswa Kelas X Ips Di Sma Negeri 1 Palembang. Jurnal Swarnabhumi, 3(2).21-25.

Sofyana, L., Rozaq, A. (2019). Pembelajaran Daring Kombinasi Berbasis Whatsapp Pada Kelas Karyawan Prodi Teknik Informatika Universitas Pgri Madiun. Jurnal Nasional Pendidikan Teknik Informatika, 8,(1),8.

Sulistiono, M. (2019). Implementasi Hybrid Learningmenggunakan Aplikasi Edmodopada Matakuliah Model Penelitian Kualitatif. Jurnal Ilmiah Pendidikan Dasar Islam, 1,(1), 15.

Sutarna, N. (2016). Penerapan Model Penugasan Untuk Meningkatkan Kemampuan Memahami Peta Pada Siswa Sekolah Dasar. Jurnal Pendidikan Geografi, 16.(1) 2433.

Tambak, S. (2016) Model Resitasi dalam Pembelajaran Pendidikan Agama Islam. Jurnal Al-hikmah, 13, (1).

Wiharto, M. (2020) sistem Pembelajaran Daring Di Perguruan Tinggi, jurnal universitas esa unggu,3(1).31-34 